\title{
Acoustic and satellite remote sensing of blue whale seasonality and habitat in the Northeast Pacific
}

\author{
Jessica C. Burtenshaw ${ }^{\mathrm{a}, *}$, Erin M. Oleson ${ }^{\mathrm{a}}$, John A. Hildebrand ${ }^{\mathrm{a}}$, Mark
} A. McDonald ${ }^{\mathrm{a}}$, Rex K. Andrew ${ }^{\mathrm{b}}$, Bruce M. Howe ${ }^{\mathrm{b}}$, James A. Mercer ${ }^{\mathrm{b}}$

${ }^{a}$ Marine Physical Laboratory, Scripps Institution of Oceanography, University of California San Diego, La Jolla, CA 92093-0205, USA ${ }^{\mathrm{b}}$ Applied Physics Laboratory, University of Washington, Seattle, WA 98105, USA

Received 16 September 2002; accepted 8 September 2003

Available online 9 September 2004

\begin{abstract}
Northeast Pacific blue whales seasonally migrate, ranging from the waters off Central America to the Gulf of Alaska. Using acoustic and satellite remote sensing, we have continuously monitored the acoustic activity and habitat of blue whales during 1994-2000. Calling blue whales primarily aggregate off the coast of southern and central California in the late summer, coinciding with the timing of the peak euphausiid biomass, their preferred prey. The northward bloom of primary production along the coast and subsequent northbound movements of the blue whales are apparent in the satellite and acoustic records, respectively, with the calling blue whales moving north along the Oregon and Washington coasts to a secondary foraging area with high primary productivity off Vancouver Island in the late fall. El Niño conditions, indicated by elevated sea-surface temperature and depressed regional chlorophyll- $a$ concentrations, are apparent in the satellite records, particularly in the Southern California Bight during 1997/1998. These conditions disrupt biological production and alter the presence of calling blue whales in primary feeding locations. Remote sensing using acoustics is well suited to characterizing the seasonal movements and relative abundance of the northeast Pacific blue whales, and remote sensing using satellites allows for monitoring their habitat. These technologies are invaluable because of their ability to provide continuous large-scale spatial and temporal coverage of the blue whale migration. (C) 2004 Elsevier Ltd. All rights reserved.
\end{abstract}

\section{Introduction}

Blue whales (Balaenoptera musculus) are found in all the world's oceans, and are known to migrate

\footnotetext{
*Corresponding author. Tel.: + 1-858-822-4609; fax: + 1858-534-6849.

E-mail address: jburtenshaw@mpl.ucsd.edu (J.C. Burtenshaw).
}

long distances on a seasonal cycle. A vocally distinct population of blue whales inhabit the northeast Pacific, ranging from the Gulf of Alaska to waters off Central America, based on the continuity of photo-ID matches, satellite-tag data, and acoustic recordings (Calambokidis et al., 1999; Mate et al., 1999; Gregr et al., 2000; Stafford et al., 1999b, 2001). Individuals found within the Gulf of California, Mexico, are also thought to be 
part of this larger northeastern group, based on photo-identification matches off central California (Calambokidis et al., 1990) and vocalization types (Thompson et al., 1996). The cyclic annual migration of the northeastern Pacific blue whale population is associated with feeding at mid- to high-latitudes throughout the highly productive summer and fall, followed by a southbound migration to tropical regions to give birth and mate in the winter and spring. Details of their complete migration route, timing, and possible segregation by gender or maturity remain unknown. Although this population was severely depleted by commercial hunting, their population appears to be recovering, currently estimated at about 2000 individuals using capture-recapture photo-ID methods and 3000 individuals using linetransect methods (Calambokidis and Barlow, 2004), with an estimated growth rate of $6 \%$ in 1995 (Barlow, 1995). Large aggregations are often observed throughout the summer and fall feeding on patches of euphausiids near the California Channel Islands and Monterey Bay, regions known for high biological productivity (Croll et al., 1998; Fiedler et al., 1998; Schoenherr, 1991).

Acoustic and satellite remote sensing is well suited to characterizing the seasonal movements and habitat of northeast Pacific blue whales given the large scale of their seasonal migration. Passive acoustic detection using fixed hydrophones distributed throughout the northeast Pacific provides the large-scale spatial and temporal coverage needed to characterize the migratory patterns of calling blue whales. Satellite imagery provides an efficient means for monitoring oceanic conditions such as surface chlorophyll- $a$ levels and seasurface temperatures (SST), which serve as indicators of blue whale habitat quality. Satellitederived SST and chlorophyll- $a$ concentrations reveal the seasonality of upwelling and the progression of phytoplankton blooms along the west coast of North America (Kahru and Mitchell, 2000; Chavez et al., 2002).

Through remote sensing, we have continuously monitored the acoustic activity of blue whales and their habitat during 1994-2000 using data from six sites. Our analysis suggests that calling blue whales primarily aggregate offshore of central and south- ern California in the mid-summer and fall. A less dense, but important region of aggregation occurs offshore of Vancouver Island later in the season, from late summer through winter. Primary production off southern California typically peaks in the spring allowing particular euphausiid species to grow to maturity by summer, coinciding with the arrival of blue whales. As the phytoplankton bloom proceeds north along the coast, so do the aggregations of calling whales, with a time lag of several months. Anomalous oceanographic conditions, such as El Nño, disrupt primary productivity (Kahru and Mitchell, 2000), euphausiid distribution and abundance (Tanasichuk, 1998a, b; Marinovic et al., 2002), and alter the seasonality of calling blue whale presence in these primary feeding locations.

\section{Background}

\subsection{Northeast Pacific blue whale calls}

A trait common to blue whales worldwide is the production of high intensity, low frequency, long duration acoustic calls that are produced in repetitive patterns or songs (McDonald et al., 2003). The study of blue whale calls provides a means for characterizing various blue whale population movements. In an environment where visibility is limited and individuals may be widely dispersed, the benefits of communicating through acoustic calls that propagate for up to hundreds of kilometers are apparent (Payne, 1995). The unique call pattern of northeast Pacific blue whales distinguishes them from other blue whale populations around the world, including the northwest Pacific blue whales (Stafford et al., 2001), and may be a primary guide for intragroup recognition for mating or group cohesion. In this paper we use blue whale call intensity as a proxy for population density, although we recognize that call production may be gender specific (McDonald et al., 2001; Croll et al., 2002) or have other seasonal or behavioral correlates.

Northeast Pacific blue whale calls have both pulsed and tonal components. The first, or "A", call unit is pulsive with a duration of about $20 \mathrm{~s}$. It 
has a fundamental frequency of about $16 \mathrm{~Hz}$ and overtones at five additional frequencies, with a particularly strong overtone near $88 \mathrm{~Hz}$. The second, or "B", call unit consists of 20 s of slightly down-swept, harmonically related tones with a fundamental frequency at $16 \mathrm{~Hz}$ and prominent third harmonic at $48 \mathrm{~Hz}$. These calls are often repeated in an alternating sequence by individual animals. The low frequencies, coupled with a loud source level (186 dB re: iP at 1-m) (McDonald et al., 2001), enable these "A-B" call sequences to propagate great distances, and to be detected at $600 \mathrm{~km}$ range using an array of hydrophones (Stafford et al., 1999a). For several months each year, these calls are the dominant oceanic ambient noise in the northeast Pacific at their tonal frequencies (Curtis et al., 1999).

A previous blue whale monitoring study used acoustic recordings from the US Navy SOund SUrveillance System (SOSUS) arrays in the north Pacific and deployed hydrophones in the Eastern Tropical Pacific to monitor the distribution of northeast Pacific blue whale calls through 1996 and 1997 (Stafford et al., 2001). The northeast Pacific blue whale call type was recorded along the west coast of North America from July through December 1996, and in the Eastern Tropical Pacific primarily from February to May 1997, though it was heard at a lower level throughout the year at this southern location, indicating that a portion of the population refrained from the mass annual migration north (Stafford et al., 2001). Hydrophones in the central North Pacific region received these call types minimally throughout all of 1996, though not in November. This study demonstrated both north-south and east-west movement of calling blue whales throughout segments of an annual migration in the northeastern Pacific. While Stafford et al. (1999b) also used acoustic data from 1993 to 1997 to outline the general migration route and timing of vocalizing northeast Pacific blue whales at the far north and south of their migration, our study aims to contribute the seasonality of vocalizing aggregations along the central part of their northward migration and the interannual variability throughout anomalous oceanographic conditions.

\subsection{Blue Whale prey}

The distribution and movement of blue whales in the California Current (CC) region has been linked with zooplankton aggregations, in particular the euphausiid species Euphausia pacifica and Thysanoessa spinifera (Schoenherr, 1991; Croll et al., 1998; Fiedler et al., 1998). The distribution of E. pacifica and T. spinifera extends from the Gulf of Alaska to southern California, with complementary offshore and near-shore ranges, respectively (Brinton, 1976). Both species occupy relatively "cold" water and may be limited in their southern extent by the temperature of the mixed layer (Brinton, 1981). Their distributions and densities have been observed to change with altered oceanographic conditions, such as those brought about by El Niño (Brinton, 1981; Mackas, 1995; Tanasichuk, 1998a, b; Marinovic et al., 2002).

Euphausiid larvae occupying southern California waters are produced locally, and their growth coincides spatially and temporally with the upwelling season. The upwelling proceeds north along the coast and is followed by major euphausiid larval recruitment (Brinton, 1976). There are distinct spawning bouts throughout the year, and the relatively high success of the large spring cohort is closely related to the increased level of primary production available following typical spring upwelling (Brinton, 1976; Tanasichuk, 1998a). Although cohort analysis of E. Pacifica off southern California has shown differential survivorship and growth rates of cohorts throughout the year, maximum population biomass often occurs during the summer and early-fall (Brinton, 1976). A time lag, on the order of seven months, has been observed between the onset of environmental conditions that facilitate primary production and the maturation of grazing euphausiids from the major spring cohorts (Brinton, 1976).

\subsection{Oceanographic setting}

Blue whale feeding grounds off the west coast of North America are associated with the California Current System (CCS) - a zone of high primary 
productivity. The CC typically transports nutrientrich water from the north in a broad offshore surface-flow along the coast. Wind-driven coastal upwelling, particularly strong in the spring, introduces cool, nitrogen-rich, sub-surface waters from below into the euphotic zone. The structure of the continental shelf and coastal winds create mixing and nutrient recycling. Variations in the southward mass transport of nutrient-rich waters of the CC has been correlated to variations in local zooplankton abundance, and is thus argued to be integral to primary production (Chelton et al., 1982). By making nutrients available for uptake by phytoplankton, favorable conditions are created for abundant grazing zooplankton (Chelton et al., 1982; McGowan, 1984, 1985; McGowan et al., 1998). Both wind driven upwelling and southward transport typically add nutrients into surface waters and combine to extend the highly productive zone far offshore seasonally. Along the northern portion of the CCS, a southward jet develops next to the coast with strong alongshore winds in the summer, then moves offshore through the fall, in the form of meanders and closed eddies (Strub and James, 2000). River outlets along the coast, such as the Juan de Fuca Strait off British Columbia and the Columbia River off Washington, provide additional nutrients locally, especially concentrated during heavy rainfall (Mackas et al., 1978; Crawford and Dewey, 1989; Mackas, 1992).

In the Southern California Bight, shelf breaks south of Point Conception, island slopes of the Channel Islands, and nearby seamounts create turbulence, mixing and increased surface nutrients that support dense aggregations of primary and secondary production, including euphausiids (Fiedler et al., 1998). Additional regional upwelling is created by small and meso-scale cyclonic eddies in the converging currents, causing euphotic zone nutrient loads and primary productivity to increase and be laterally entrained at times; these eddies are clearly detectable throughout the year in satellite imagery of sea-surface roughness, SST, and surface chlorophyll (DiGiacoma and Holt, 2001). The strongest equatorward winds along the California coast occur in the spring, and larger cyclonic eddy-like circulation entrains the nutri- ents and productivity to remain within the California Bight. The combination of these physical and biological components create and maintain the relatively high biological productivity typical of this region.

\subsection{El Niño Southern Oscillation}

Bisecting the span of this study, a strong El Niño Southern Oscillation (ENSO) event modified oceanographic conditions in the eastern Pacific during 1997-1998. The influence of extreme ENSO events on biological activity affects organisms of many trophic levels, including phytoplankton, zooplankton, pelagic fish, crabs, seabirds, and marine mammals. Ecological studies have noted shifts in community structure where southern (warm water) species extended their geographic range into northern waters, some even displacing the typical species in the northeast Pacific (McGowan et al., 1998).

ENSO events are associated with a change in atmospheric pressure over the Pacific basin, causing the equatorial trade winds to decrease or even reverse (blowing west-east), the westward equatorial current to slow and the eastward equatorial undercurrent to strengthen (Chavez et al., 1999). Within months of these atmospheric changes, as deep long-period Kelvin waves traverse the equatorial Pacific, the thermocline levels throughout the Pacific shoals in the west and deepens in the east (Feely et al., 2002). When these deep-water waves reach the eastern Pacific, notable propagation of these coastally trapped waves proceeds poleward (Smith, 1983; Collins et al., 2002; Peterson et al., 2002; Ryan and Noble, 2002). Additionally, the altered thermocline causes diminished coastal upwelling from below the deepened thermocline in the eastern Pacific. Anomalously warm waters occur northward along the coast of North America in addition to a decrease in the southward transport of rich subarctic water, thereby decreasing primary productivity detectable via satellite imagery (Kahru and Mitchell, 2000; Goes et al., 2001) and zooplankton biomass in the CC (Chelton et al., 1982; McGowan, 1984, 1985; Lavaniegos et al., 1998; Marinovic et al., 2002). Following the 
1997-1998 El Niño was a La Niña year (1999), marked by anomalously low SST and increased chlorophyll- $a$ concentrations during the spring bloom (Goes et al., 2001). The spatial extent of the 1999 phytoplankton bloom was the largest ever documented in the equatorial Pacific (Chavez et al., 1999).

\subsection{Habitat studies using remote sensing}

Past studies have used satellite imagery to investigate relationships between marine mammals and their habitat. Recently, Morre et al. (2002) found the northwestern Pacific blue whales consistently associated with increased surface chlorophyll concentrations in the spring, and with cold SST and SST fronts from spring to fall, suggesting these are key features of productive zones for feeding blue whales. They also found that boundary currents, eddies, and bathymetric features, such as seamounts and slopes, were focal habitat for vocalizing blue whales throughout the year, suggesting that features linked with elevated productivity are key habitat to enable feeding year-round. Similarly, Jaquet et al. (1996) confirmed the existence of a correlation between surface chlorophyll concentration and sperm whale density, based on contemporary ocean color imagery and historical whaling records at various temporal (2-12 months) and spatial $\left(220-1780 \mathrm{~km}^{2}\right)$ scales, finding the degree of correlation increased with increased spatial scales. They provided evidence for a time lag of at least 4 months and a spatial lag between peak chlorophyll levels and peak sperm whale densities, due to interactions traversing at least four trophic levels. Additionally, Woodley and Gaskin (1996) observed an association between right and fin whale habitat and satellite derived SSTs in the North Atlantic.

Within the CCS, Smith et al. (1986) found the distribution of various cetacean species linked to regional sea-surface chlorophyll variability, derived from ocean-color data. While they encountered low numbers of blue whales throughout their study, elevated concentrations were observed in two highly productive areas, the Pioneer Seamounts, off central California, and near Tanner and Cortez Banks, among the California Channel Islands. Similarly, Mate et al. (1999) tracked the movements of 10 blue whales on their summer feeding grounds in the Southern California Bight in 1994 and 1995 using satellite tags. Within the bight, individuals were clustered or moved in a zigzag pattern, suggesting feeding or foraging behavior, respectively. Tags that remained attached for extended periods revealed larger-scale movements, tracking one individual north to Cape Mendocino, California, and four individuals south along Baja California, Mexico, one of which continued south near the Costa Rica Dome. Our study continues to explore the link between northeastern Pacific blue whales and their habitat.

\section{Methods}

\subsection{Acoustic monitoring}

Acoustic monitoring provides continuous data on blue whale calling that allows for determination of the seasonality and the geographic range of calling individuals. Acoustic census techniques provide a proxy measure of the relative whale abundance within a region throughout the season, based on the occurrence of calls and the detection range of the acoustic sensors.

From 1994 through 2000, nearly continuous acoustic data were collected from SOSUS arrays in the North Pacific. Data used in this study were originally collected by the Acoustic Thermometry of Ocean Climate (ATOC) project, to monitor ambient noise, then later collected as a component of the North Pacific Acoustic Laboratory (NPAL) project (Howe et al., 1995). At 5-min intervals, $170 \mathrm{~s}$ of acoustic data were sampled at $2000 \mathrm{~Hz}$ from single hydrophones at each array. The data from these 5-min intervals were subdivided into 10 groups (32,768 samples per group) and the power spectra for each group were averaged and smoothed over $1 \mathrm{~Hz}$ bins from 0 to $500 \mathrm{~Hz}$. Gaps that occur in the time series are owing to equipment malfunctions or damage to the submarine cables connecting the hydrophones to shore. Evaluation of these data as 5-min averaged spectra, provides seasonal calling trends for 
blue and fin whales, as well as noise due to shipping and wind (Curtis et al., 1999). It should be noted that averaged acoustic data provide aggregate population calling activity and cannot be used to monitor single calling animals in space or time. These arrays are mounted on the continental slope, positioned to receive sound from within the deep sound channel. Watkins et al. (2000a) demonstrated that blue whale calls can be detected by these acoustic arrays at over $500 \mathrm{~km}$ distance using beamformed data from several hydrophones, although we estimate our detection area using averaged spectral data from individual hydrophones is on the order of $20-40 \mathrm{~km}$.

To quantify the relative seasonal blue whale call abundance at six sites along the west coast of North America, we extracted the blue whale call energy (amplitude of blue whale calls above ambient) from the spectra by applying an automated detection algorithm to the data averaged into 12-h bins. The blue whale call detection algorithm extracts the power within the fundamental frequency $(16 \mathrm{~Hz})$ and the third harmonic $(48 \mathrm{~Hz})$ of the blue whale " $\mathrm{B}$ " call in comparison to nearby ambient noise levels. The algorithm is highly defensive against false detection by comparing the signal intensity in the frequency bands of blue whale calls against adjacent ambient noise and by applying a threshold of minimum power for detection. The detection output produces a time series of the $48 \mathrm{~Hz}$ "B" call intensity over local ambient levels, to avoid seasonally overlapping fin whale calling near the $16 \mathrm{~Hz}$ component. We further reviewed the output of the algorithm to remove periods where ships or storms distorted the signal-to-noise ratio, affecting our ability to clearly detect and classify the blue whale calls. For example, Fig. 1 shows one year of acoustic spectra data from offshore southern California, along with the corresponding output of the blue whale call detection algorithm. The geographic locations of acoustic monitoring sites are depicted in Fig. 2 (fall). The close proximity of the two southern California hydrophones might cause some overlap in acoustic detection ranges, though we believe this to be minimal.

\subsection{Oceanographic monitoring with satellite sensors}

Despite variable water column dynamics both regionally and seasonally, surface estimates derived from satellite-mounted sensor data are used in this study as a proxy for relative regional primary production and surface temperatures at the sites of acoustic monitoring. Global chlorophyll- $a$ concentration estimates of the oceans' upper layers are produced and archived by NASA using the Sea-viewing Wide Field-of-view Spectroradiometer (SeaWiFS) ocean-color sensor with the most current processing algorithms (Patt et al., 2003). This sensor is mounted on the OrbView- 2 satellite, which has maintained nearly global coverage every two days since August 1997. The spectroradiometer measures the radiance backscattered by the earth's surface within eight spectral bands, ranging from visible to infrared light. By measuring the spectral character of the light reradiated from the ocean's euphotic zone and using various ancillary data, chlorophyll- $a$ concentrations can be estimated to gauge phytoplankton production and accumulation in the surface waters. Improvements in net coverage and quality during the most recent reprocessing resulted from changes in level-3 spatial binning, navigation algorithms, glint correction, chlorophyll failure flags, cloud and ice flags, stray light masks, atmospheric correction algorithm, and vicarious calibration, among others (Patt et al., 2003). They note an improved fit to in situ chlorophyll measurements to meet the original mission goal for accuracy of $\pm 35 \%$ for chlorophyll estimates.

Satellite-mounted sensors for SST estimation have been in orbit throughout the past two decades. The multi-channel sea-surface temperature (MCSST) data set has been processed with a single algorithm from November 1981 through February 2001, enabling consistency for interannual comparisons. The radiation data is obtained by an Advanced Very High Resolution Radiometer (AVHRR), mounted on each of NOAAs polarorbiting satellites (NOAA-7, 9, 11, and 14). Each sensor measures the character of the radiation within five bands (two in the infrared range, two in 


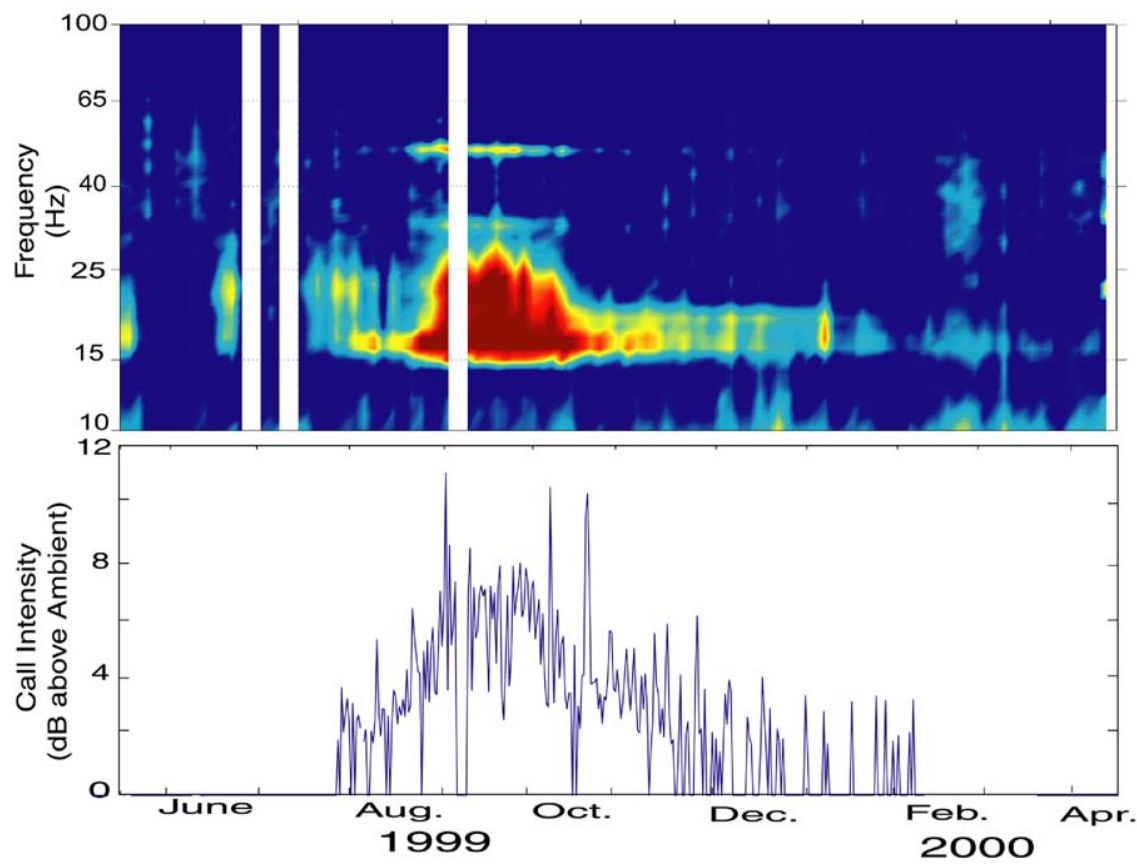

Fig. 1. Eleven months of acoustic spectral data from the southern California North site from May 1999 to March 2000 showing the seasonal trend in blue whale presence in the region. The data are initially processed into 5-minute averages, and have been further processed into 3 day averages for this spectrogram. The presence of calling blue whales is indicated by the high intensity bands at 16 , 32 , and $48 \mathrm{~Hz}$. The lower panel is the output of the blue whale detector algorithm run on 12 hour averaged spectra.

the visible range, and one thermal), after which the data are sent to a ground station to be processed. These values are converted to SST estimates and displayed as $18-\mathrm{km}$ resolution weekly composites based on eight-days of data (with one day of overlap between weeks). A global study comparing AVHRR-based MCSSTs against ship-based measurements found minimal biases of $0.3-0.4^{\circ} \mathrm{C}$ (MCSST lower than ship) and standard deviations of $0.5-0.6^{\circ} \mathrm{C}$ (McClain et al., 1985).

We tracked surface chlorophyll- $a$ concentrations using 9-km resolution, gridded, eight-day SeaWiFS composites (processed with version OC4v4), from its onset in August 1997-2000. Similarly, we tracked SSTs using 18-km resolution, weekly AVHRR MCSST composites from 1994 through 2000. Chlorophyll- $a$ and SST were measured within non-overlapping zones around each acoustic array; however, the close proximity of the two southern California hydrophones required that we use the same zone in this instance (Fig. 2 , spring). The monitored zones extend along the coast and well offshore to account for oceanographic conditions surrounding each site that might affect blue whale prey abundance and distribution. We extracted the mean values as well as the minimum and maximum within each region using the imaging software WIM (Kahru, 2000). We excluded estimates from regions having less than $5 \%$ coverage of valid pixels due to cloud coverage, to avoid unrepresentative classifications. We then compared the varied oceanographic conditions throughout the study zones with the timing and character of blue whale calling at each site. To visualize the phytoplankton blooms and movements of calling whales, we created an animated time-series of regional eight-day chlorophyll composites with overlaid relative call detection levels at each site (see additional supplementary data available online). 


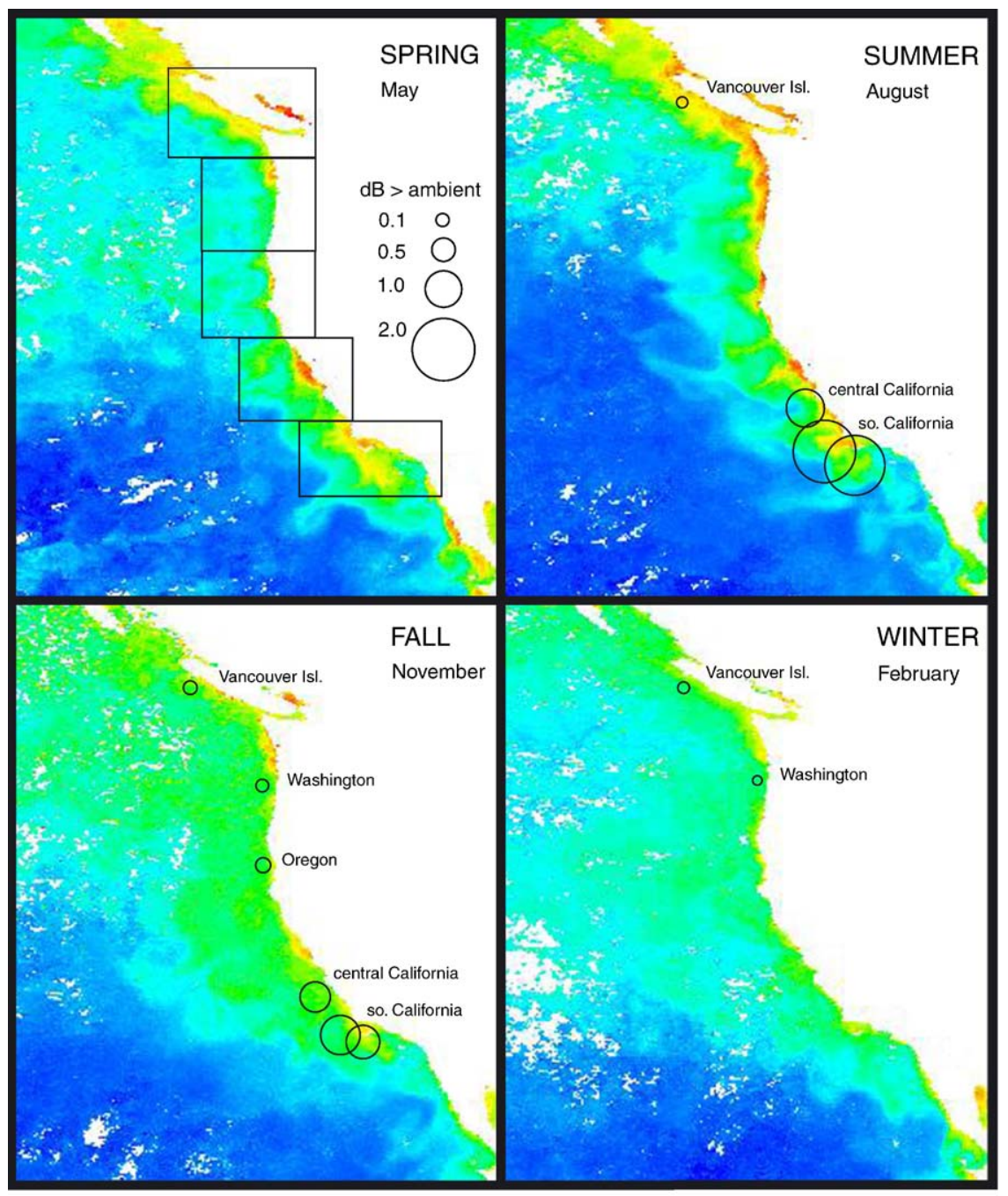

Fig. 2. Surface chlorophyll composites derived from SeaWiFS images over one-month intervals are displayed with seasonal averages of blue whale calling intensities. The panels of chlorophyll- $a$ concentration are monthly composites from 2000 chosen to best illustrate typical seasonal conditions throughout the study region. The boxed regions on the Spring panel depict the zones of data extraction from both chlorophyll and SST imagery. The locations of the acoustic arrays are from Curtis et al. (1999). Differential seasonal blue whale calling intensity is indicated by the size of the ring at each acoustic monitoring location; absence of a ring at a given acoustic monitoring site indicates a lack of calling detected. The rings on the Spring panel show the scale of seasonally averaged call intensity in decibels above ambient for reference. The seasonal acoustic averages include acoustic data from 1994 through 2000, subdivided as follows: Spring (April-June), Summer (July-September), Fall (October-December) and Winter (January-March).

\section{Results}

\subsection{Seasonality of blue whale calls}

The hydrophone data reveal patterns of migration and seasonality for calling northeast Pacific blue whales. These data suggest that blue whales begin migrating northward in the early summer, since they are first heard offshore of southern California in early-to mid-June (Fig. 3). As the summer progresses the whales are heard further north along the central California coast in early 


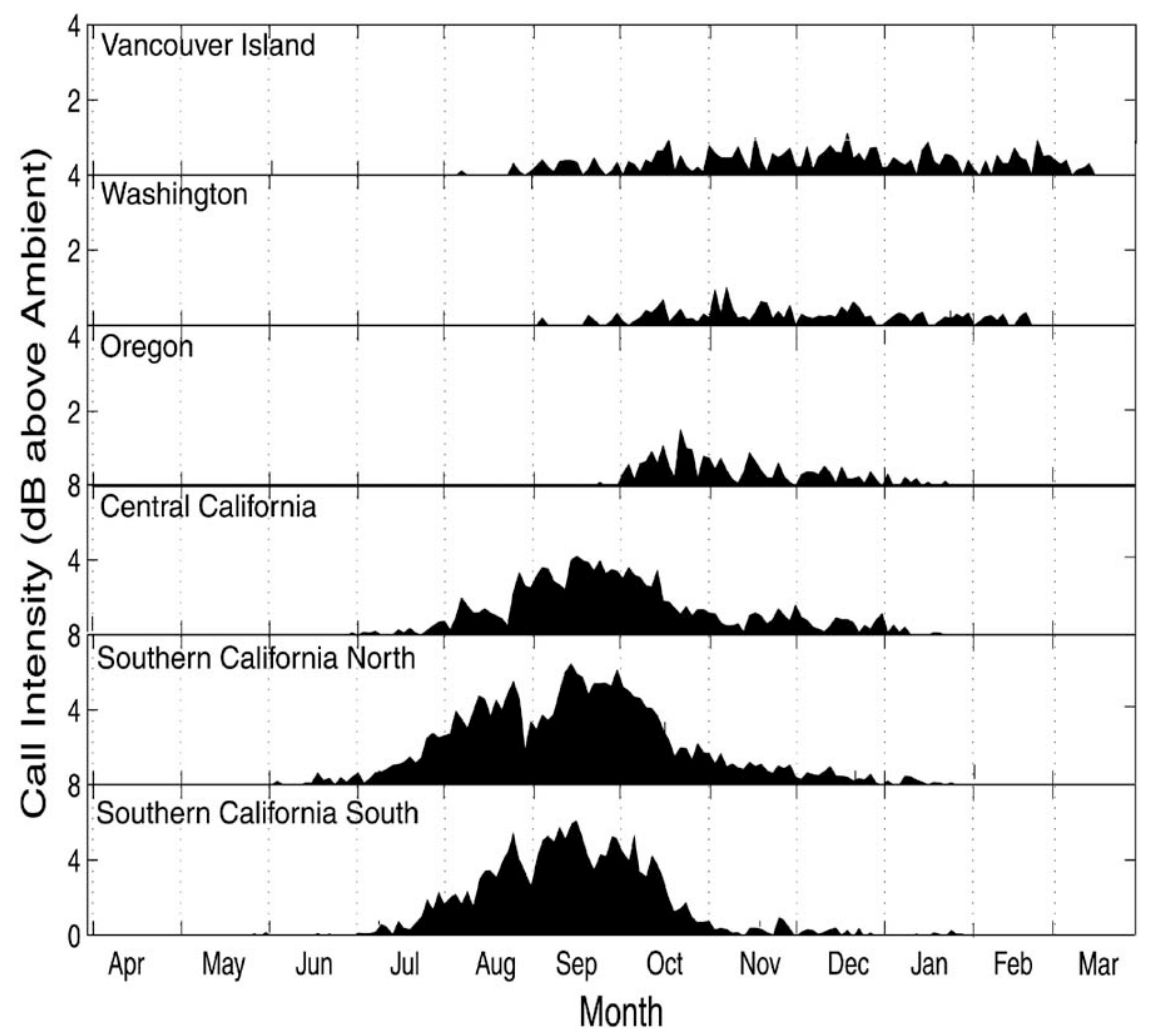

Fig. 3. Seven-year average (1994-2000) of blue whale acoustic intensity for each of six sites along the continental shelf of western North America. Acoustic data are available from hydrophones at Vancouver Island, Washington, Oregon, central California, southern California North, and southern California South. Each 12-hour data point is averaged into 2-day bins. Different acoustic intensity scales are used for the northern three and for the southern three sites, reflecting the higher level of calling at the later.

July, then offshore Oregon and Washington in September. The only deviation from a strictly northward migration is the detection of blue whales near Vancouver Island in mid-August, about one month earlier than off Washington and Oregon. A more or less northward progression is consistent for all the years for which we have data (1994-2000), with minor fluctuations in the timing of the arrival, peak, and the departure from each region.

Collective blue whale calling intensity has a pronounced peak during mid-September in southern California, and during late-September in central California (Fig. 3). At these sites, calling gradually decreases during the fall, and blue whales are rarely detected after the end of January. Call energy detected at the northern sites (Oregon,
Washington, and Vancouver Island) is significantly lower than at the southern sites, suggesting fewer calling whales are present in this region. There is typically little or no peak in blue whale detection at the northern three sites. Blue whales are detected through January off Oregon, through February off Washington, and well into March off Vancouver Island. The average number of weeks that blue whale calls are detected at the southern and central California sites is 32 weeks, while at the Oregon and Washington sites, calls span 21 weeks or less. Off Vancouver Island, the site furthest north, blue whales are heard for at least 30 weeks, similar in duration to their stay along California (Fig. 3). These data suggest that blue whale presence is focused offshore southern and central California in the summer and fall, and that 
a more temporally diffuse presence of blue whales occurs offshore Vancouver Island, and to a lesser extent Oregon and Washington in the fall and winter. While the northbound migration along the coast is easily tracked with the acoustic data, the southbound return to low latitudes is not apparent in our data set.

\subsection{Environmental patterns}

SeaWiFS imagery reveals seasonal trends in chlorophyll concentration that may aid in understanding blue whale migration patterns (Figs. 2, 4, and additional supplementary data available online). In general, chlorophyll- $a$ levels peak over the continental shelf in the spring and persist throughout the summer. The spring chlorophyll bloom precedes the timing of the observed northward migration of calling blue whales by several months.

Seasonal changes in primary productivity (chlorophyll) are related to the availability of nutrients and hence oceanographic conditions. The satellite-derived SST data show depressed surface temperatures from winter through spring (Fig. 5). Off central and southern California these cool surface temperatures precede increased chlorophyll levels of phytoplankton blooms by 1-2 months (Figs. 5 and 2-spring). The region surrounding Vancouver Island experiences a strong early-spring phytoplankton bloom. Later in the spring, less intense phytoplankton blooms progress northward from California along the coast of Oregon and Washington. High productivity in the regions off Oregon and central California may be associated with input from the Columbia River and the San Francisco Bay, respectively, while the region surrounding Vancouver Island appears to receive nutrients from the Juan de Fuca and Georgia Straits (see animation in supplementary data which is available in online version). The coastal phytoplankton bloom continues through the summer season and is advected off the shelf in highly productive jets, meanders, and eddies created by southward alongshore winds (Fig. 2, summer; Strub and James, 2000). The northern region (Washington and Vancouver Island) experiences a series of phytoplankton

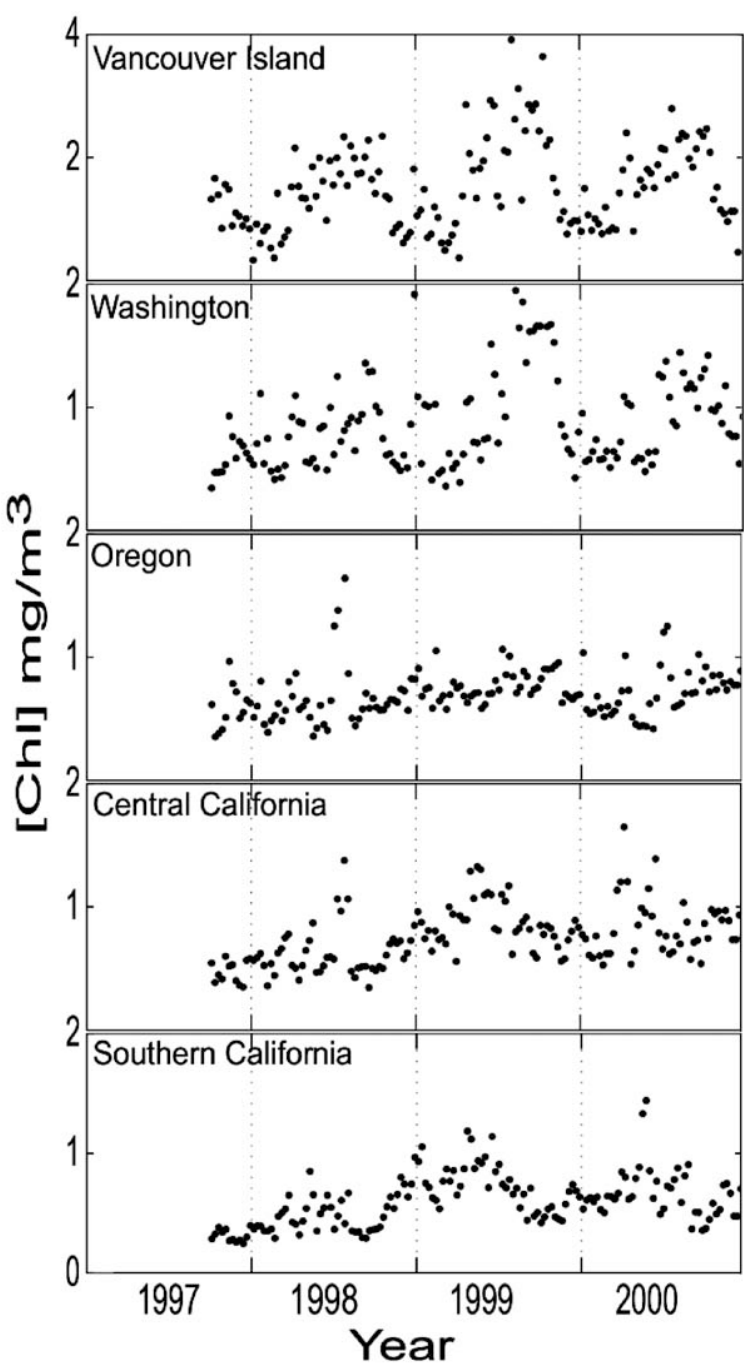

Fig. 4. Eight-day average chlorophyll- $a$ concentrations $\left(\mathrm{mg} / \mathrm{m}^{3}\right)$ for each of the five regions studied here from the onset of SeaWiFS availability in September 1997-2000. The 1998 El Niño can be seen as the absence or relative weakness of the spring phytoplankton bloom, particularly at the southern sites. Note the higher scale used to display the concentrations off Vancouver Island.

blooms over the shelf extending well into the fall (Fig. 2, fall). Phytoplankton accumulates along the entire coastal region during fall, extending well offshore in relatively high surface chlorophyll concentrations. Surface chlorophyll- $a$ levels become diffuse along the coast and decrease through the winter when they reach an annual low before 


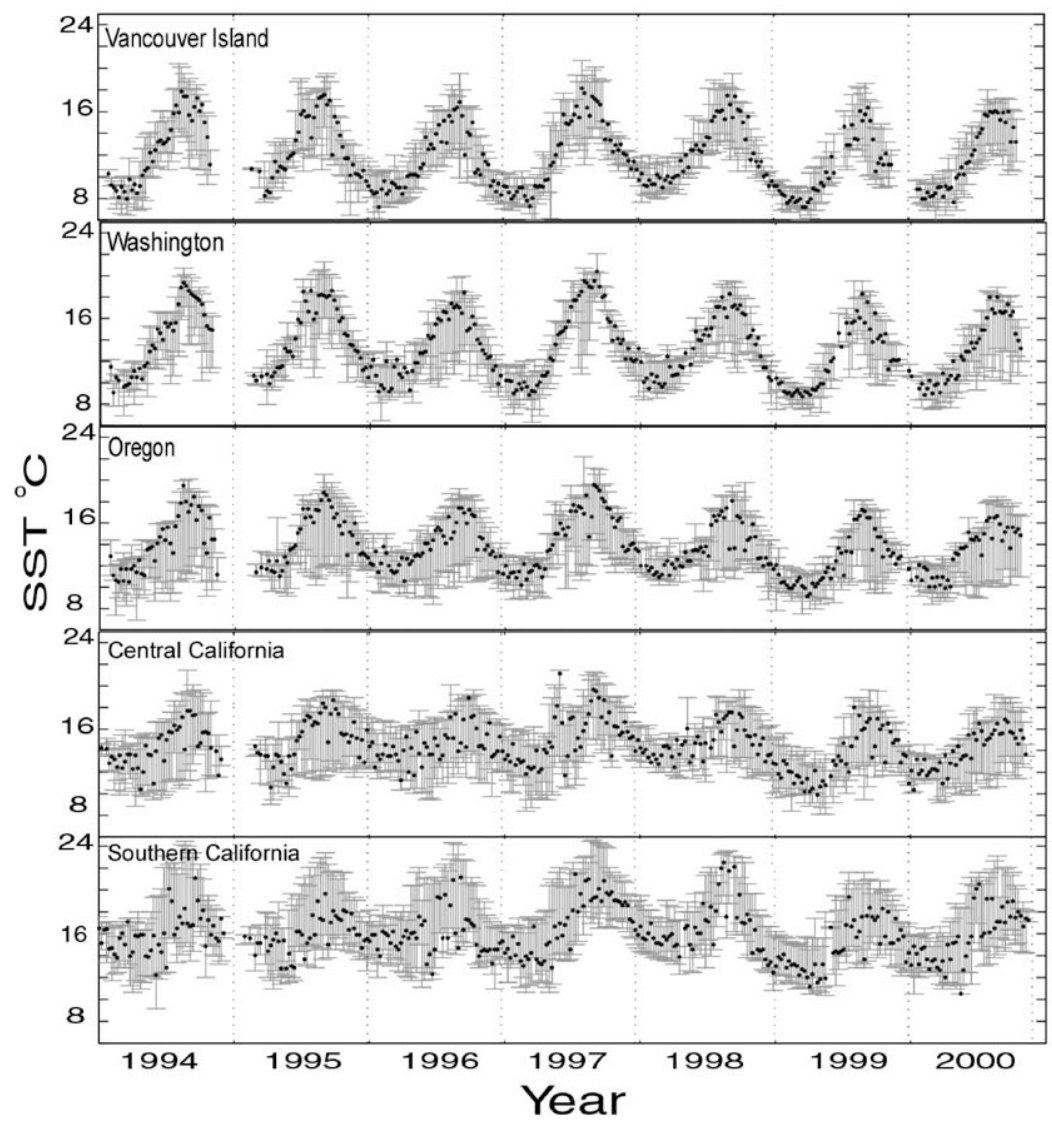

Fig. 5. Seven-day average SST values $\left({ }^{\circ} \mathrm{C}\right)$ from each of the five geographic regions studied here from 1994 to 2000 . Minimum and maximum values indicated by the gray bars. The El Niño of 1998 is seen as increased surface temperatures, particularly during the spring when upwelling usually lowers the surface temperatures substantially. Data available from: ftp://podaac.jpl.nasa.gov/pub/ seasurfacetemperature/avhrr/mcsst/data/weekly/day.

the next spring phytoplankton bloom (Fig. 2, winter). This annual process is also apparent in the time-series animation of surface chlorophyll concentrations for the study area (see supplementary data available online).

Average SSTs throughout the monitored zones display an annual variation of as much as $8{ }^{\circ} \mathrm{C}$ and are more pronounced in the northern regions (Fig. 5). Along the coast, surface temperatures increase throughout the summer, peaking in September, then decrease steadily through the end of the year. Temperatures continue to drop until an annual low is reached during the peak spring upwelling.

SeaWiFS chlorophyll imagery is unavailable prior to the summer of 1997; however, the typical seasonal SST patterns described above occurred at each site from 1994 to 1996 and in 2000, which suggests typical physical conditions (Fig. 5). Cool spring SST is evidence of increased surface nutrients from upwelling below the thermocline/ nutricline and/or southward transport, both of which stimulate photosynthesis.

\subsection{Deviations during ENSO}

Notable deviations from the aforementioned oceanographic conditions were observed during the El Niño period beginning in the summer of 1997. The largest anomalies occurred at the southern sites (Southern and Central California 
and Oregon) but were also apparent at the northern sites (Washington and Vancouver Island). Summer temperatures at the southern sites during 1997 surpassed peak surface temperatures of the previous three years by nearly $3{ }^{\circ} \mathrm{C}$ (Fig. 5). The SeaWiFS estimates from September 1997 display fall chlorophyll levels well below seasonal levels of later years (Fig. 4). The southern four sites also had notably warm fall and winter temperatures in the 1997/1998 calling season. Evidence of either weak spring upwelling or upwelling in the presence of a depressed thermocline was apparent in anomalously warm SST estimates in 1998 (by $2-4{ }^{\circ} \mathrm{C}$ ) throughout all regions (Fig. 5). The anomalously weak spring phytoplankton blooms in 1998 are seen near the coast, without much offshore drift (see supplementary data available online). The decreased offshore surface chlorophyll levels throughout the 1997/1998 El Niño are consistent with observations from other studies of this ENSO event (Kahru and Mitchell, 2000; Chavez et al., 2002).

A switch to anomalously cold surface temperatures occurred in late-fall of 1998, marking the onset of La Niña, and continued throughout 1999 (Fig. 5). Evidence of increased surface nutrient supplies from upwelling and/or increased southward transport was apparent in the elevated chlorophyll levels at most sites during the spring bloom of 1999 (Fig. 4). Chlorophyll levels remained elevated throughout the summer in a broad band stretching offshore and diminished in the fall, when more typical conditions returned in 2000 .

During the 1997/1998 El Niño, euphausiid abundance and species' distributions were altered (Marinovic et al., 2002), and the distribution and relative abundance of blue whales were altered (Fig. 6). Calling blue whales deviated from their typical migration pattern during the 1997/1998 El Niño, primarily by shifting their presence northward and by extending their stay in presumed feeding areas. Callers were present off southern California in 1998, however, their level of calling was substantially reduced during the expected mid-September peak. Calling near central California occurred at levels comparable to the previous year during the late summer and fall; however, substantial calling levels also occurred late in the season when calling usually tapers off, indicating a delayed departure from that region in 1998. The seasonal duration of calling was extended near Vancouver Island and Washington compared to previous years and the amplitude of the calling intensity was greater than expected near Vancouver Island.

The movements of calling blue whales were again altered during the highly productive oceanographic conditions of the 1999 La Niña. Southern California sites received the usual high calling intensity, however, at the northern sites (Washington and Vancouver Island), calling intensity and duration increased compared to previous years.

\section{Discussion}

\subsection{Seasonality of calling blue whales}

The strategies used by foraging blue whales to find krill swarms remain unknown; however, seeking aggregations of krill in consistently located and predictably timed concentrations may moderate some of the uncertainties inherent in foraging. Waters off southern and central California are regions of upwelling, high primary productivity, krill spawning and aggregation, as well as calling blue whale aggregation. Specific bathymetric features, such as the shelf edge and seamounts, may help to concentrate krill and therefore serve as targets for feeding blue whales within the Southern California Bight (Fiedler et al., 1998).

The arrival of blue whales off Pt. Conception in early June coincides with substantial primary productivity accumulating within and extending west from the Southern California Bight (see supplementary data available online). The September peak of calling in this region coincides with expected peak euphausiid biomass (Brinton, 1981), approximately seven months following the onset of the cool water upwelling season (Fig. 5, February- May) and typical euphausiid spawning events. Southern and central California experience a comparable influx of blue whales, probably owing to comparable primary and secondary productivity levels. 


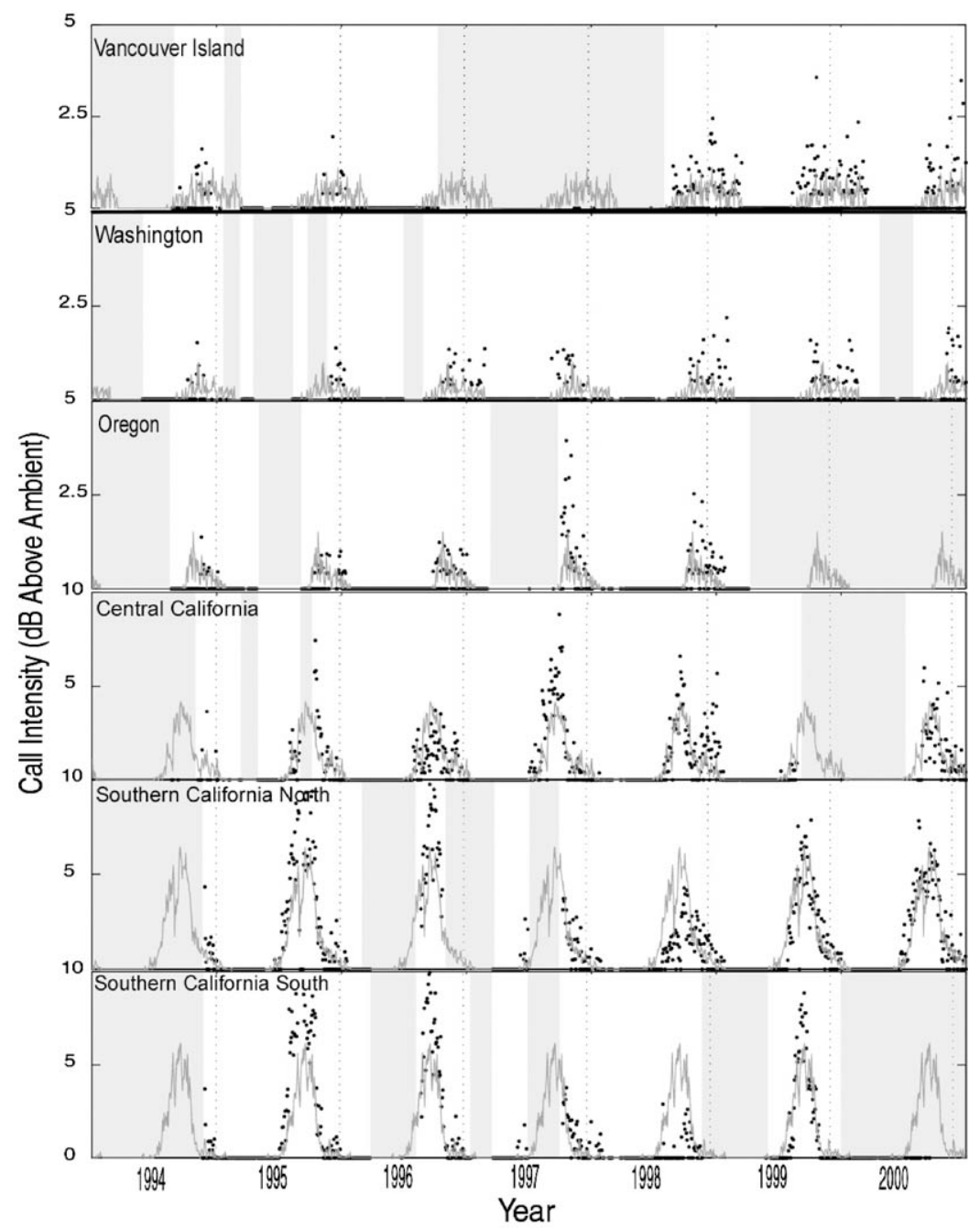

Fig. 6. Two-day average blue whale acoustic intensity in decibels $(\mathrm{dB})$ above the ambient noise level at six sites. Periods of no data are indicated as gray shaded regions on the time line of each site. The seven-year average of acoustic intensity and seasonality (from Fig. 2) is shown repeated for reference as the dark gray line on each timeline. The actual data for each 2 day period is shown as a black dot. Note the different scales used for the northern three and southern three sites.

Calling blue whales are less densely aggregated along the northern extent of the migration route from Oregon to Washington, while Vancouver Island seems to represent a secondary center for migrating callers, or perhaps resident individuals who call seasonally. There is a relatively consistent short duration of calling off Oregon, where individuals are likely passing through in transit to northern sites. The northern extent of our study region experiences a phytoplankton bloom in early-spring, when sufficient sunlight is available and northern currents and estuary outlets provide ample nutrients. Apparent strong and persistent upwelling throughout summer near Vancouver Island is seen in concentrated surface chlorophyll levels. These observations are consistent with results of an 11-year study around Vancouver Island (Mackas, 1995), where upwelled California 
Undercurrent water and Georgia Strait surface water occurred April through September, and ample nitrate inputs over the shelf were from the upper layer discharge of the Juan de Fuca Strait. Additionally, our observations of high chlorophyll levels from late-spring through fall in this region are consistent with Mackas (1992), where he also observed a mid-summer euphausiid bloom which remained concentrated over the shelf and a strong late-summer to fall peak occurrence of the two dominant euphausiid species, E. pacifica and $T$. spinifera, on the southern shelf. These phytoplankton blooms and euphausiid growth cycles are consistent with the seasonal timing of peak blue whale calling in this region.

Our acoustic data do not reveal a southward migration of blue whales. It is possible that the whales are no longer calling during their return trip south, or that they are further offshore where this study's hydrophones do not detect them. Stafford et al. (2001) analyzed acoustic data from several SOSUS sites further offshore and reported northeastern Pacific blue whale calls at low detection rates throughout the year at one site, peaking in the fall and winter, suggesting some portion of the population may be traveling further offshore and calling during their migration south.

Though blue whales off Central America have been observed foraging on euphausiid Nyctiphanes simplex and small pelagic crabs, their feeding throughout the CCS may be evidence of a necessity for the blue whale population to exploit regionally dispersed feeding grounds. The relatively large size of the northern latitude euphausiid species might attract foraging whales as it does migrating hake, who preferentially feed on large individuals of the same euphausiid species in northern waters during the summer (Tanasichuk, 1999).

\subsection{ENSO anomalies}

During El Niño, the decreased calling amplitude in the southern sites and the anomalously increased calling presence in the north suggest that the ENSO related anomalies altered prey in the south, while the north remained productive. It appears that during the 1997/1998 El Niño event, fewer areas maintained the primary productivity necessary to support euphausiid aggregations and thus grazing blue whales. The southern California sites appeared to host fewer calling blue whales throughout the 1998 season, while central California received an influx in calling intensity and duration. Likewise, near Vancouver Island, blue whales were heard at increased intensity for at least 30 weeks during 1998 and 1999. Similar increases in calling duration off Washington in 1998 and 1999 suggest either increased prey availability or increased northern movements by the whales searching for prey. Calling whales arrived at the northern sites earlier than usual, likely seeking prey. While Washington and Vancouver Island historically hosted numerous blue whales, they have been observed only in sparse numbers since being depleted by whaling in the early 1900s (Gregr et al., 2000). Their increased presence in 1998 and 1999, suggested both by calling amplitude and seasonal duration, is evidence for reutilization of resources in the northern latitudes by an increasing number of blue whales. There is a relatively consistent short duration of calling off Oregon, apparently not affected by the changes during ENSO, suggesting that individuals are merely passing through in transit to the northern sites.

Although Brinton (1976) suggests that the biomass of large euphausiid adults is determined by the spring upwelling strength of the previous year, the northward shift of blue whales in 1998, suggests that the effects of decreased spring upwelling on euphausiid biomass off southern California may be apparent within the same year. Other factors involved may include varied life history strategies of single euphausiid species, which might display slower growth for a longer duration in sub-arctic waters, compared to faster maturation of krill off California (Brinton, 1976). Euphausiid counts of $T$. spinifera and E. pacifica throughout southern California appear to decrease during El Niño events (CalCOFI data, 2002). Additionally, overall zooplankton counts were well below average during the El Niños of 1958, $1982 / 1983$, and 1993, though net samples were noted to bias sampling of larval stages likely due to net escape by adults (CalCOFI data, 2002). 
It is interesting to directly compare the timing and peak of blue whale calling off central California with a study of euphausiid aggregation densities and demographics off Monterey Bay from May through November, 1997-1999 (Marinovic et al., 2002). Demographic analysis of $E$. pacifica aggregations show they were consistently adult-dominated from summer through fall, with exceptions in September and November of 1999, where adolescents were the dominant age-class. The switch to mostly adult assemblages occurred in July of 1997 and 1998, coinciding with the arrival of vocalizing blue whales, which also persist through the fall in this region. When blue whale calling was near maximum levels in September of 1997, Marinovic et al. (2002) note a huge drop in density of both E. pacifica and T. spinifera, and a subsequent drop in $N$. simplexa density the following month, suggesting that the whales' grazing might have had a significant impact on the euphausiid populations. Only E. pacifica were present in substantial clusters throughout the 1998 surveys, and incurred density drops in July and October, coinciding with the arrival and peak of blue whale calling periods, respectively. In addition, though euphausiid data is not available throughout the winter, both E. pacifica and $T$. spinifera were increasing in density through November of 1998, the year blue whales delayed their departure from this region. Again, the arrival of calling blue whales in July of 1999, is coincident with large drops in adult-dominated assemblages of both E. pacifica and T. spinifera; however, an acoustic data gap prevents further comparisons.

Benson et al. (2002) also observed changes in the cetacean distributions using line-transect surveys throughout the Monterey Bay from 1996 to 1999. They note the local rorqual abundance, dominated by humpbacks but also including finbacks and blues, parallels the krill abundance. Nearshore productive zones, such as Monterey Bay, may have become productive refuges for both zooplankton (Marinovic et al., 2002) and rorquals (Benson et al., 2002; this study).

An alternative explanation of altered blue whale calling during the El Niño warming period may be a change in behavior. Evidence exists that feeding and calling may be mutually exclusive activities. A decrease in blue whale calling intensity may result from an increase in feeding and/or foraging behavior, rather than a decrease in the number of whales present. If calling is used by males to attract mates (McDonald et al., 2001; Croll et al., 2002), during periods of scarce food resources more effort may be spent foraging as opposed to attracting a mate. A decrease in regional calling intensity during El Niño may suggest a change in blue whale behavior as opposed to their absence.

Watkins et al. (2000b) observed a clear deviation from typical behavior of vocalizing humpbacks in the northeast Pacific during their annual migrations throughout this ENSO event, when compared to previous winters. He noted increased humpback songs at high latitudes in the central and northeast Pacific throughout the El Niño fall and winter compared to the prior two years, additional evidence that key regions provided productive refuges to foraging rorquals. While humpbacks feed on both euphausiids and fish, the effects of El Niño appear to be far-reaching throughout the food chain.

Euphausiid abundance fluctuations have been observed to affect the survival of various predators at high latitudes. For example, short-tailed shearwaters (Puffinus tenuirostris) over the southeastern Bering Sea shelf experienced a mass mortality due to starvation in the summer of 1997, when atypical atmospheric and oceanographic conditions caused decreased availability of their euphausiid prey (Baduini et al., 2001). Sockeye salmon (Oncorhyncus nerka), who also feed on euphausiids, had poor returns to Bristol Bay with lower than typical weights of survivors, in the summer of 1997 (Kruse, 1998). Similarly, Tynan (1998) found the Bering Sea right whale population had shifted their typical prey species and foraging grounds in the southeast Bering Sea during the 1997/1998 El Niño. She observed them uncharacteristically feeding over the middle shelf in the summer of 1997, which experienced increased surface temperatures $\left(2-4{ }^{\circ} \mathrm{C}\right)$ and an anomalous coccolithophore bloom, observed through SeaWiFS imagery (Tynan, 1998), compared to their usual feeding on calenoid copepod species in deep water along the shelf break (Nemoto, 1963). Anomalous atmospheric and oceanographic conditions affect many 
species among varied trophic levels within the coastal and pelagic ecosystems (Napp and Hunt, 2001; Stockwell et al., 2001).

It is important that anomalous oceanic conditions be evaluated within the context of regime shifts, decadal oscillations, and other large scale variables. For example, Hunt et al. (2002) proposed that the pelagic ecosystem control in the Bering Sea alternates between primarily bottomup during cold regimes and top-down in warm regimes. They note that repeated years of deleterious cold-water effects on zooplankton, which have limited production in extremely cold water, cause subsequent low juvenile fish survival, and tends to cause multiple predatory fish to be limited by scarce resources; whereas multiple warm years in the Bering allow ample abundance of phytoplankton and zooplankton to support strong fish recruitment, after which the predatory fish will eventually limit the abundance of the foraging fish. However, they also note the potential for piscivorous sea birds and mammals to thrive in cold regimes, with less competition from piscivorous fish. The ecosystem approach of Hunt et al. (2002), examining the varied control mechanisms throughout regime shifts and anomalous atmospheric fluxes, is helpful for evaluating varied effects on individual species within a larger context.

The 1997/1998 El Niño occurs within a warm regime in what is considered to be larger decadal oscillations. Interdecadal oscillations have been governing a warming trend causing the surface waters to be elevated in the CCS since 1977, tracked by the Pacific Decadal Oscillation (PDO) index (Mantua et al., 1997). Ryan and Noble (2002) note a tendency for more extreme ENSO events to occur during warm decadal regimes. This oscillation may also be responsible for a biological regime shift among the zooplankton species, favoring a warm regime set of zooplankton including euphausiids, over the displaced cool regime (McGowan et al., 1998). It is noteworthy that the timing of northeastern Pacific blue whale population recovery coincides with this warm regime of increased krill abundance in the CCS region, as well as international agreement to limit whaling. Additional monitoring on various temporal and spatial scales would improve our understanding of environmental effects on this species, with its vast geographical range, potentially long life-span, and late sexual maturation (low rate of reproduction).

\subsection{Scale and variable selection}

Gregr and Trites (2001) used whaling records to model critical habitat for five whale species in waters off British Columbia, exploring six predictor variables (month, depth, slope, depth class, SST, and salinity). The habitat model for blue whales was relatively insensitive to the predictor variables, partially due to the small sample size for this species. However, they were able to predict slight concentrations of blue whales off the shelf of Vancouver Island and the Queen Charlotte Islands, areas that we have found to be high in primary productivity (Figs. 2 and 4) several months prior to the arrival of calling blue whales in that region (Figs. 2, 3, and 6). Our study suggests that their modeling could be enhanced with the inclusion of satellite derived continuous data and a larger sample size for blue whales, both of which are provided by remote sensing.

The scale of our study is large compared to that of Gregr and Trites (2001), which assessed $10 \times$ $10 \mathrm{~km}^{2}$ boxes. We acoustically monitored up to several tens of $\mathrm{km}$ from each sensor and oceanographically monitored a substantially larger area around each acoustic sensor. We chose a large spatial scale to monitor oceanographic conditions because of the time lag occurring between trophic interactions, and therefore spatial lag between oceanographic variables and whale presence. Phytoplankton are at least two trophic levels away from blue whales, and the euphausiids have a maturation time of at least a few months, suggesting that monitoring concurrent chlorophyll and blue whale abundance may produce weak correlations. Gregr and Trites (2001) suggest that if animal distributions are a function of prey concentration caused by small scale eddies or gyres, little spatial or temporal lag would be expected; however, while euphausiids are concentrated by these circulation events, a time lag is required for them to reach a size appropriate for blue whale consumption, and therefore larger 
spatial scales or small scales including a time lag must be incorporated into the analysis. A multiscale analysis, such as that by Jaquet et al. (1996), will be necessary to adequately describe blue whale habitat, particularly using only chlorophyll- $a$ and SST as predictor variables. Large scale is also necessary to observe the effects of El Niño on regional primary productivity. Our supplementary data (Appendix A) which is available online illustrates that a substantial phytoplankton bloom did occur off the coast of North America in the spring of 1998; however, its spatial extent was limited to nearshore and therefore the overall productivity of the region was below normal. This effect may not have been observed if smaller areas were chosen for the analysis.

The goal of our study was to identify the relationship between satellite-derived oceanographic variables and acoustic proxies for whale presence. The temporal and spatial scales for both satellite and acoustic monitoring are well matched to the task of developing whale habitat models. Both satellite and acoustic monitoring provide continuous data, enabling analysis of the time lag between primary productivity and whale presence. The large spatial coverage of oceanographic and acoustic monitoring allows for the study of highly variable oceanographic environments and shifting whale presence. We have included only two of many variables available from satellite-derived oceanographic data. The addition of other variables, such as bathymetry, slope, sea-surface height, sea-surface roughness (wind speed), thermocline depth, and isotherm depth may increase the predictive power of future models.

\section{Conclusions}

The advent of remote sensing technology, both satellite and acoustic, has increased our ability to monitor and study blue whales and their habitat. Since sound production is an important aspect of blue whale behavior, passive acoustics are an ideal way to continuously monitor their presence and movements. The spatial and temporal coverage provided by remote sensing surpass the abilities of ship-based environmental measurements and visual marine mammal observations.

The analysis presented here relates environmental parameters with calling blue whale presence and migration. Advances in acoustic census techniques and the addition of other satellite derived environmental parameters may permit more quantitative associations between blue whale distribution and habitat. Continuous satellitederived oceanographic measures allow for the introduction of time lags into the analysis so that associations between habitat and acoustic activity can be modeled. These models are needed to better predict blue whale foraging grounds and other critical habitat.

\section{Acknowledgements}

We thank Ed Brinton for consultation on krill life history, and Mati Kahru for invaluable advice on the use of satellite data. We thank the SeaWiFS Project and the NASA Distributed Active Archive Center at the Goddard Space Flight Center for the production and distribution of the SeaWiFS data and the Jet Propulsion Laboratory at the Physical Oceanography Distributed Active Archive Center (PO.DAAC) for producing and making available the SST data set. This work was supported by the Strategic Environmental Research and Development Program (SERDP) under the Conservation Program managed by Robert Holst, by the Office of Naval Research under Jeff Simmen, and by the Chief of Naval Operations N45 under Frank Stone and Ernie Young.

\section{Appendix A. Supplementary data}

The online version of this article contains additional supplementary data. Please visit doi: 10.1016/jdsr2.2004.06.020.

\section{References}

Baduini, C.L., Hydrenbach, K.D., Coyle, K.O., Pinchuk, A., Mendenhall, V., Hunt, G.O., 2001. Mass mortality of short- 
tailed shearwaters in the south-eastern Bering Sea during summer 1997. Fisheries Oceanography 10 (1), 117-130.

Barlow, J., 1995. The abundance of cetaceans in California waters: Part 1. Ship surveys in summer and fall of 1991. Fishery Bulletin 93, 1-14.

Benson, S.R., Croll, D.A., Marinovic, B.B., Chavez, F.P., Harvey, J.T., 2002. Changes in the cetacean assemblages of a coastal upwelling ecosystem during El Niño 1997-98 and La Nina 1999. Progress in Oceanography 54, 279-291.

Brinton, E., 1976. Population biology of Euphausia pacifica off southern California. Fishery Bulletin 74 (4), 733-762.

Brinton, E., 1981. Euphausiid distributions in the California Current during the warm winter-spring of 1977-1978, in the context of a 1949-1966 time series. CalCOFI Reports 22, 135-154.

Calambokidis, J., Steiger, G.H., Cubbage, J.C., Balcomb, K.C., Ewald, C., Kruse, S., Wells, R., Sears, R., 1990. Sightings and movements of blue whales off central California 1986-1988 from photo-identification of individuals. Report of the International Whaling Commission (special issue 12), 343-348.

Calambokidis, J., Chandler, T., Rasmussen, K., Steiger, G.H., Schlender, L., 1999. Humpback and blue whale photographic identification research off California, Oregon, and Washington, in 1998. Final report to Southwest Fisheries Science Center, available from Cascadia Research, 218 1/2 W. Fourth Ave., Olympia, Wa 98501, 35pp.

Calambokidis, J., Barlow, J., 2004. Abundance of blue and humpback whales in the eastern North Pacific estimated by capture-recapture and line-transect methods. Marine Mammal Science 20 (1), 63-85.

CalCOFI data, 2002. Zooplankton Volume-Distributions. Research from Scripps Institution of Oceanography WWW Page, http://calcofi.org/data/zooplankton/6-seasonalcycles.htm.

Chavez, F.P., Strutton, P.G., Friederich, G.E., Feely, R.A., Feldman, G.C., Foley, D.G., McPhaden, M.J., 1999. Biological and chemical response of the equatorial Pacific Ocean to the 1997-98 El Niño. Science 286 (5447), 2126-2131.

Chavez, F.P., Pennington, J.T., Castro, C.G., Ryan, J.P., Michisaki, R.P., Schlining, B., Walz, P., Buck, K.R., McFadyen, A., Collins, C.A., 2002. Biological and chemical consequences of the 1997-1998 El Niño in central California waters. Progress in Oceanography 54, 205-232.

Chelton, D.B., Bernal, P.A., McGowan, J.A., 1982. Large-scale interannual physical and biological interaction in the California Current. Journal of Marine Research 40 (4), 1095-1125.

Collins, C.A., Castro, C.G., Asanuma, H., Rago, T.A., Han, S.K., Durazo, R., Chavez, F.P., 2002. Changes in the hydrography of central California waters associated with the 1997-98 El Niño. Progress in Oceanography 54, 129-149.

Crawford, W.R., Dewey, R.K., 1989. Turbulence and mixing: sources of nutrients on the Vancouver Island continental shelf. Atmosphere-Ocean 27, 428-442.
Croll, D.A., Tershy, B.R., Hewitt, R.P., Demer, D.A., Fielder, Smith, S.E., Armstrong, W., Popp, J.M., Kiekhefre, T., Lopez, V.R., Urban, J., Gendron, D., 1998. An integrated approach to the foraging ecology of marine birds and mamals. Deep-Sea Research II 45, 1353-1371.

Croll, D.A., Clark, C.W., Acevedo, A., Tershy, B.R., Flores, R.S., Gedamke, J., Urban, R.J., 2002. Only male fin whales sing loud songs. Nature 417, 809.

Curtis, K.R., Howe, B.M., Mercer, J.A., 1999. Low-frequency ambient sound in the North Pacific: long time series observations. Journal of the Acoustical Society of America 106 (6), 3189-3200.

DiGiacoma, P.M., Holt, B., 2001. Satellite observations of small coastal eddies in the Southern California Bight. Journal of Geophysical Research 106 (C10), 22,521-22,543.

Feely, R.A., Boutin, J., Cosca, C.E., Dandonneau, Y., Etcheto, J., Inoue, H.Y., Ishii, M., LeQuete, C., Mackey, D.J., McPhaden, M., Metzl, N., Poisson, A., Wanninkhof, R., 2002. Seasonal and interannual variability of $\mathrm{CO}_{2}$ in the equatorial Pacific. Deep-Sea Research II 49, 2443-2469.

Fiedler, P.C., Reilly, S.B., Hewitt, R.P., Demer, D., Philbrick, V.A., Smith, S., Armstrong, W., Croll, D.A., Tershy, B.R., Mate, B.R., 1998. Blue whale habitat and prey in the California Channel Islands. Deep-Sea Research II 45, $1781-1801$.

Goes, J.I., Gomes, H.R., Limsakul, A., Balch, W.M., Saino, T., 2001. El Niño related interannual variations in biological production in the North Pacific as evidenced by satellite and ship data. Progress in Oceanography 49, 211-225.

Gregr, E.J., Trites, A.W., 2001. Prediction of critical habitat for five whale species in the waters of coastal British Colombia. Canadian Journal of Fisheries Aquatic Science 58, 1265-1285.

Gregr, E.J., Nichol, L., Ford, J.K.B., Ellis, G., Trites, A.W., 2000. Migration and population structure of northeastern Pacific blue whales off coastal British Colombia: an analysis of commercial whaling records from 1908-1967. Marine Mammal Science 16 (4), 699-727.

Howe, B.M., Anderson, S.G., Baggeroer, A., Colosi, J.A., Hardy, K.R., Horwitt, D., Karig, F.W., Leach, S., Mercer, J.A., Metzger, K., Olson, L.O., Peckham, D.A., Reddaway, D.A., Ryan, R.R., Stein, R.P., Von der Heydt, K., Watson, J.D., Weslander, S.L., Worcester, P.F., 1995. Instrumentation for the Acoustic Thermometry of Ocean Climate (ATOC) prototype Pacific Ocean network. In: Oceanus '95 Proceedings, San Diego, CA, 9-12 October, 1995, pp. 1483-1500.

Hunt, G.L., Stabeno, P., Walters, G., Sinclair, E., Brodeur, R.D., Napp, J.M., Bond, N.A., 2002. Climate change and control of the southeastern Bering Sea pelagic ecosystem. Deep-Sea Research II 48, 5821-5853.

Jaquet, N., Whitehead, H., Lewis, M., 1996. Coherence between 19th century sperm whale distributions and satellite-derived pigments in the tropical Pacific. Marine Ecology Progress Series 145, 1-10.

Kahru, M., 2000. Windows Image Manager-Image display and analysis program for Microsoft Windows with special 
features for satellite images. Available at WWW page, http://wimsoft.com.

Kahru, M., Mitchell, G., 2000. Influence of the 1997-98 El Niño on the surface chlorophyll in the California Current. Geophysical Research Letters 27, 2937-2940.

Kruse, G.H., 1998. Salmon run failures in 1997-1998: a link to anomalous ocean conditions? Alaska Fisheries Resource Bulletin 5, 55-63.

Lavaniegos, B.E., Gomez-Gutierrez, J., Lara-Lara, J.R., Hernandez-Vazquez, S., 1998. Long-term changes in zooplankton volumes in the California Current System the Baja California region. Marine Ecology Progress Series 169, 55-64.

Mackas, D.L., 1992. Seasonal cycle of zooplankton off Southwestern British Columbia: 1979-89. Canadian Journal of Fisheries Aquatic Science 49, 903-921.

Mackas, D.L., 1995. Interannual variability of the zooplankton community off southern Vancouver Island. Canadian Special Publication Fisheries Aquatic Science 121, 603-615.

Mackas, D.L., Louttit, G.C., Austin, M.J., 1978. Spatial distribution of phytoplankton and zooplankton in British Columbia coastal waters. Canadian Journal of Fisheries Aquatic Science 37, 1476-1487.

Mantua, N.L., Hare, S.R., Zhang, Y., Wallace, J.M., Francis, R.C., 1997. A Pacific interdecadal climate oscillation with impacts on salmon production. Bulletin of the American Meteorological Society 78, 1069-1079.

Marinovic, B.B., Croll, D.A., Gong, N., Benson, S.R., Chavez, F.P., 2002. Effects of the 1997-1999 El Niño and La Niña events on zooplankton abundances and euphausiid community composition within the Monterey Bay coastal upwelling system. Progress in Oceanography 54, 265-277.

Mate, B.R., Lagerquist, B.A., Calambokidis, J., 1999. Movements of North Pacific blue whales during the feeding season off southern California and their southern fall migration. Marine Mammal Science 15 (4), 1246-1257.

McClain, E.P., Pichel, W.G., Walton, C.C., 1985. Comparative performance of AVHRR-based multichannel sea surface temperatures. Journal of Geophysical Research 90, 11587-11601.

McDonald, M.A., Calambokidis, J.C., Terinishi, A., Hildebrand, J.A., 2001. The acoustic calls of blue whales off California with gender data. Journal of the Acoustical Society of America 109, 1728-1735.

McDonald, M.A., Hildebrand, J.A., Mesnick, S.L., 2003. Biogeographic characterization of blue whale song worldwide: using song to identify populations. Presented to the IWC Scientific Committee May 2003, Berlin SC/55/SH7.

McGowan, J.A., 1984. The California El Niño. Oceanus 27 (2), $48-51$.

McGowan, J.A., 1985. El Niño 1983 in the southern California bight. In: Wooster, W.S., Fluiharty, D.L. (Eds.), Washington Sea Grant Program. Seattle, pp. 166-184.

McGowan, J.A., Cayan, R.C., Dorman, L.M., 1998. Climateocean variability and ecosystem response in the northeast Pacific. Science 281, 210-217.
Morre, S.E., Watkins, W.A., Daher, M.A., Davies, J.R., Dalheim, M.E., 2002. Blue whale habitat associations in the northwest Pacific: analysis of remotely-sensed data using Geographic Information System. Oceanography 15 (3), 20-25.

Napp, J.M., Hunt, F.L., 2001. Anomalous conditions in the south-eastern Bering Sea 1997: linkages among climate, weather, ocean, and biology. Fisheries Oceanography 10 (1), 61-68.

Nemoto, T., 1963. Some aspects of the distribution of Calanus cristatus and Calanus plumehrus in the Bering and its neighboring waters, with reference to the feeding of baleen whales. Scientific Reports of the Whales Research Institue Tokyo 17, 157-170.

Patt, F.S., Barnes, R.A., Eplee Jr., R.E., Franz, B.A., Robinson, W.D., Feldman, G.C., Bailey, S.W., Gales, J., Werdell, P.J., Wang, M., Frouin, R., Stumpf, R.P., Arnone, R.A., Gould Jr., R.W., Martinolich, P.M., Ransibrahmanakul, V., O'Reilly, J.E., Yoder, J.A., 2003. Algorithm Updates for the Fourth SeaWiFS Data Reprocessing. NASA Tech. Memo. 2003-206892, In: Hooker, S.B., Firestone, E.R. (Eds.), vol. 22, NASA Goddard Space Flight Center, Greenbelt, Maryland, 74pp.

Payne, R., 1995. Among whales. In: Payne, R. (Ed.). Scribner, New York, p. 431.

Peterson, W.T., Keister, J.E., Feinberg, L.R., 2002. The effects of the 1997-1999 El Niño/La Niña events on hydrography and zooplankton off the central Oregon coast. Progress in Oceanography 54, 381-398.

Ryan, H.F., Noble, M., 2002. Sea level response to ENSO along the central California coast: how the 1997-1998 event compares with the historic record. Progress in Oceanography $54,149-169$.

Schoenherr, J.R., 1991. Blue whales feeding on high concentrations of euphausiids around Monterey Submarine Canyon. Canadian Journal of Zoology 69, 583-594.

Smith, R.L., 1983. Peru coastal currents during El Niño: 1976 and 1982. Science 221 (4618), 1397-1399.

Smith, R.C., Dustan, P., Au, D., Baker, K.S., Dunlap, E.A., 1986. Distribution of cetaceans and sea-surface chlorophyll concentrations in the California Current. Marine Biology 91, 385-402.

Stafford, K.M., Fox, C.G., Clark, D.S., 1999a. Long-range acoustic and localization of blue whale calls in the northeast Pacific. Journal of Acoustical Society of America 104 (6), 3616-3625.

Stafford, K.M., Nieukirk, S.L., Fox, C.G., 1999b. An acoustic link between blue whales in the eastern tropical Pacific and the northeast Pacific. Marine Mammal Science 15 (4), $1258-1268$.

Stafford, K.M., Nieukirk, S.L., Fox, C.G., 2001. Geographic and seasonal variations of blue whale calls in the North Pacific. Journal of Cetacean Resource Management 3 (1), 65-76.

Stockwell, D.A., Whitledge, T.E., Zeeman, S.I., Coyle, K.O., Napp, J.M., Vrodeur, R.D., Alexei, I.P., Hunt, G.L., 2001. Anomalous conditions in the south-eastern Bering Sea, 
1997: nutrients phytoplankton and zooplankton. Fisheries Oceanography 10 (1), 99-116.

Strub, P.T., James, C., 2000. Altimeter-derived variability of surface velocities in the California Current System: 2. Seasonal circulation and eddy statistics. Deep-Sea Research II $47,831-870$.

Tanasichuk, R.W., 1998a. Interannual variations in the population biology and productivity of Euphausia pacifica in Barkley Sound, Canada, with special reference to the 1992 and 1993 warm ocean years. Marine Ecology Progress Series 173, 163-180.

Tanasichuk, R.W., 1998b. Interannual variations in the population biology and productivity of Thysanoessa spinifera in Barkley Sound, Canada, with special reference to the 1992 and 1993 warm ocean years. Marine Ecology Progress Series 173, 181-195.

Tanasichuk, R.W., 1999. Interannual variations in the availability and utilization of euphausiids as prey for Pacific hake (Merluccius productus) along the south-west coast of Vancouver Island. Fisheries Oceanography 8 (2), $150-156$.
Thompson, P.O., Findley, L.T., Vidal, O., Cummings, W.C., 1996. Underwater sounds of blue whales, Balaenoptera musculus, in the Gulf of California, Mexico. Marine Mammal Science 12 (2), 288-292.

Tynan, C.T., 1998. Redistributions of cetaceans in the Southeast Bering Sea relative to anomalous oceanographic conditions during the 1997 El Niño. Marine Ecology Progress Series 173, 163-180.

Watkins, W.A., Daher, M.A., Reppucci, G.M., George, J.E., Martin, D.L., DiMarzio, N.A., Gannon, D.P., 2000a. Seasonality and distribution of whale calls in the North Pacific. Oceanography 13, 62-67.

Watkins, W.A., Daher, M.A., George, J.E., Haga S., 2000 b. Distribution of calling blue, fin, and humpback whales in the North Pacific. Technical Report No. WHOI-00-12, Woods Hole Oceanographic Institution, Woods Hole MA 02543, 46pp.

Woodley, T.H., Gaskin, D.E., 1996. Environmental characteristics of North Atlantic right and fin whale habitat in the lower Bay of Fundy, Canada. Canadian Journal of Zoology $74,75-84$. 